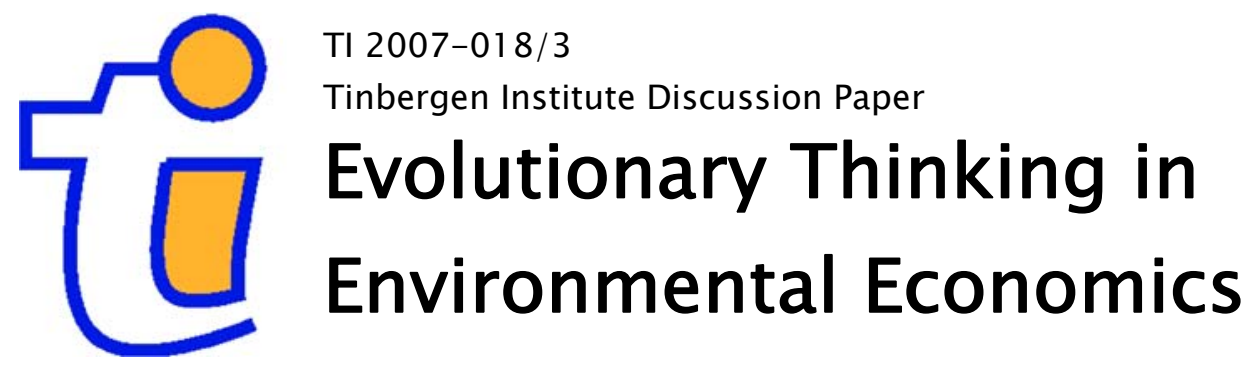

Jeroen C.J.M. van den Bergh

Vrije Un iversiteit Amsterdam, and Tinbergen Institute. 


\section{Tinbergen Institute}

The Tinbergen Institute is the institute for economic research of the Erasmus Universiteit Rotterdam, Universiteit van Amsterdam, and Vrije Universiteit Amsterdam.

Tinbergen Institute Amsterdam

Roetersstraat 31

1018 WB Amsterdam

The Netherlands

Tel.: $\quad+31(0) 205513500$

Fax: $\quad+31(0) 205513555$

Tinbergen Institute Rotterdam

Burg. Oudlaan 50

3062 PA Rotterdam

The Netherlands

Tel.: $\quad+31(0) 104088900$

Fax: $\quad+31(0) 104089031$

Most TI discussion papers can be downloaded at http:/ /www.tinbergen.nl. 


\title{
Evolutionary Thinking in Environmental Economics
}

\author{
Jeroen C.J.M. van den Bergh \\ Faculty of Economics and Business Administration \\ \& Institute for Environmental Studies \\ Free University \\ De Boelelaan 1105 \\ 1081 HV Amsterdam, The Netherlands
}

Phone: 31-20-5986164

Fax: 31-84-7384538

jbergh@feweb.vu.nl 


\begin{abstract}
Evolutionary and environmental economics have a potentially close relationship. This paper reviews past and identifies potential applications of evolutionary concepts and methods to environmental economics. This covers a number of themes: resource use and ecosystem management; growth and environmental resources; economic and evolutionary progress; and individual behavior and environmental policy. The treatment will cover both biological and economic - including institutional, organizational and technological - evolutionary phenomena. Attention will be drawn to the fact that evolutionary economics shows a surprising neglect of environmental and natural resource factors.
\end{abstract}

Keywords: Coevolution, economic growth, environmental policy, innovation, progress, selfregulation, renewable resources, resilience, social preferences.

JEL codes: B52, O3, O4, Q2, Q5. 


\section{Introduction}

Under the umbrella of economics as a broad discipline, the subdisciplines 'evolutionary economics' and 'environmental economics' (including 'resource economics') have developed quite independently. These two fields share many characteristics and can be combined in a fruitful way. They both make use of certain insights from biology, in particular ecology. In the case of environmental economics, this is illustrated best by the study of renewable resource use and ecosystem management. In the case of evolutionary economics, the biological inspiration expresses itself most clearly in the use of notions and mechanisms originating from population theory. This paper intends to show that environmental economics can greatly benefit from approaches and insights of evolutionary economics in addressing a number of core issues, both in fundamental and policy research domains. In addition, it will be argued that the study of certain themes within evolutionary economics could benefit from giving more explicit attention to the role of environmental and resource factors.

Although one might think that environmental (and resource) economics is occupied predominantly by applied policy issues, it in fact addresses a number of rather fundamental research questions. These relate to the persistence of many environmental externalities, the place of humans in the biosphere, the role of ethics and (monetary) values, and the limits to regulating the behavior of humans and economic organizations. In all these domains, evolutionary notions play a role, be it at a biological or economic (including institutional and technological) level. Not surprisingly, because of the fundamental issues involved, heterodox schools are well represented in the environmental debate, including within environmental economics. Not surprisingly, environmental economics has proven to be an important source of fundamental critique on mainstream economics (e.g., Daly and Cobb, 1989). Ecological economics, next to being a platform for multidisciplinary research, has tried to accommodate the various critiques and offer viable alternatives (van den Bergh, 2001). This new 'field' is indeed very close in spirit to evolutionary economics, in a number of ways. Dissatisfaction with neoclassical mainstream theory was an important reason for the emergence of either field. Both evolutionary and ecological economics cover a range of disciplinary angles, in addition to the dominant economics angle, such as development studies, geography, ecology and hydrology in the case of ecological economics, and technology studies, management theory, behavioral economics, evolutionary modelling and economic history in the case of evolutionary economics. Most importantly, generalized - non-genetic - evolutionary theory has been proposed by many influential 'ecological economists' as the main framework to realize a full understanding of the complex 
dynamics of interactions between human and natural systems (Boulding, 1978; Norgaard, 1984; Faber and Proops, 1990; Costanza et al., 1993; Ayres, 1994; Gowdy, 1994).

Environmental economics, and more so ecological economics, are not only subdisciplines of economics, but at the same time part of the broad field of environmental sciences. It is surprising and a missed opportunity that evolutionary thought - both genetic and non-genetic - has been so rarely invoked to allow us to understand better the causes of environmental problems as well as the characteristics of and limits to solutions. With some notable exceptions (see especially Section 3), natural scientists within the environmental sciences seem to have focused attention on practical issues (e.g., pollution effects in food webs), thus neglecting fundamental evolutionary aspects. Many social scientists working within the environmental sciences often are not well informed about evolutionary thought, and some even adopt the old-fashioned idea that evolution is a 'dangerous and explosive' notion within the realm of the social sciences. This misplaced political correctness does more harm than good, as it goes along with a focus on proximate causes of environmental degradation, misinterpreting or even overlooking the ultimate causes. As a result, one may easily arrive at ineffective or counter-productive policy suggestions. It is perhaps good to emphasize that evolutionary thought is a-political, and can be as easily (mis)used to support left-wing ideals (e.g., inequality is a tendency of evolutionary economic systems - its correction requires robust public institutions) as right-wing ideals (inequality is an inevitable outcome of evolution - learn to live with it).

In a very informative overview of the meaning of evolution for the environmental sciences, Penn (2003) surveys the evolutionary explanations of "why humans are ecologically destructive, overpopulate, overconsume, exhaust common pool resources, discount the future, and respond maladaptively to modern environmental hazards.” (Penn, 2003, p1). He notes that evolutionary biology provides fundamental insights into various environmentally relevant aspects of human behavior, such as cooperation, morality and reproduction. Regarding the latter, it is evident that population pressure is an important factor of human overexploitation of the natural environment, not only in particular regions characterized by extreme food and water shortages, but increasingly so at the global scale. A very general perspective arising from evolutionary thinking is that human-induced environmental degradation can be interpreted as the human species being maladapted to its current natural environment. Maladaptation may even get worse since the environment is not exogenous but is being transformed by humans at an unprecedented rate.

The remainder of this article is organized as follows. Section 2 mentions the most important contributions in environmental economics that have adopted an evolutionary approach. In addition, it briefly evaluates mainstream environmental economics on the basis of 'evolutionary 
criteria', and summarizes the main similarities and distinctions among environmental economics, 'ecological economics' and evolutionary economics. Section 3 examines the implications of evolutionary analysis at the level of ecosystems and natural resources, and suggests that the notion of 'resilience' can be useful to evolutionary economics. Section 4 considers economic growth with environment and resources from an evolutionary angle, and argues that major transitions in human-economic history can only be fully understood if the coevolutionary role of environmental resources is sufficiently recognized. Section 5 discusses the notion of economic progress in an evolutionary context. It presents a number of interpretations of evolutionary progress and indicates various reasons for not expecting such progress always to occur. Next, Section 6 presents an evolutionary perspective on environmental regulation. Section 7 concludes.

\section{The current state of evolutionary thinking in environmental economics}

In the previous section, the relevance of evolutionary thinking in environmental economics has been motivated. Nevertheless, the diffusion of evolutionary theory, models and insights in this field has been rather slow. This may alter by fostering communication with the field of evolutionary economics. In order to examine the common basis, we briefly summarize the small number of studies in environmental economics that have already made use of evolutionary concepts, theories and models. This covers the relevant inclusion of biological evolution (especially in resource economics) or economic evolution (including institutional and technological).

Environmental and ecological economics both are concerned with the economic analysis of the causes and the nature of environmental problems and their solutions. Environmental economics is often defined as covering resource economics as well, as many resource problems are closely related to environmental issues. This is illustrated by the use of fossil energy, which not only depletes the use of scarce resources but also causes our climate to change. An integrated treatment of environment and resources has become more pressing since the notion of sustainable development was widely adopted during the 1990s. Economists have also picked up this challenge. Few contributions have, however, explicitly tried to link evolution to sustainable development (Mulder and van den Bergh, 2001).

Environmental economics emerged during the 1960s, and employed the method of applied welfare economics. Originally, it was under the strong influence of agricultural and resource economics, especially in the USA. The early development of environmental economics occurred along three research themes. First, the technique of cost-benefit analysis (CBA) was used to evaluate investment projects with significant environmental impacts. Many of these related to 
water quality and flooding of rivers. The focus on monetary accounting through CBA stimulated the development and application of monetary valuation techniques (beginning with hedonic pricing and travel cost, and later contingent valuation) to value environmental changes, damages, projects, and policy scenarios. Parallel to this, environmental policy theory was developed, aimed at the evaluation, comparison and design of instruments of regulatory policy. This focused attention on the efficiency (welfare maximizing or cost-minimizing) character of such instruments. Last but not least, economic growth and resource scarcity received much attention in theoretical and empirical studies. On the one hand, this was part of a wider growth debate that involved other disciplines as well. On the other hand, it had strong ties with a rapidly growing literature on resource economics. This addressed the theoretical analysis of optimal resource extraction and the testing of resource scarcity using a range of indicators reflecting physical conditions, costs or prices. Resource economics covers both nonrenewable fossil fuels, metal ores and minerals and renewables, such as water, forestry and fisheries.

Traditional environmental and resource economics is very much dominated by neoclassical microeconomics. This is most clearly exemplified by the theories of monetary valuation (Johansson, 1987) and environmental policy (Baumol and Oates, 1988). Evolutionary approaches did not receive any systematic attention before the 1990s. In this period, along with the rise of attention for sustainable development, 'ecological economics' was founded as a new field of research (Costanza, 1991), representing a more pluralistic, multidisciplinary and eclectic approach, aimed at taking the best of all possible worlds. It has been quite successful in an institutional sense, as shown by a well-cited journal (Ecological Economics), many book publications, regular conferences and workshops, and a large international society (http://www.ecoeco.org/). Ecological economics integrates elements of economics, ecology, geography, political science, thermodynamics, ethics, and various other natural and social sciences. Its methodological approaches are very much embedded in the use of physicalbiological indicators and comprehensive systems analysis. Next to providing a forum for multidisciplinary environmental research, ecological economics covers a number of heterodox approaches to traditional environmental economics problems. Evolutionary economics is one of these.

How should one evaluate the currently dominant neoclassical welfare-oriented approach in environmental economics on the basis of evolutionary criteria? For this purpose, it is good to consider the main themes, namely environmental policy theory, resource economics, the theory of growth with environment and resources, and monetary environmental valuation. Environmental policy theory (Baumol and Oates, 1988) assumes perfectly rational agents and assigns a central 
role to efficiency - or more narrowly, cost-effectiveness - of policy instruments. Innovation is not central to it, while diversity of technical options, multidimensional selection beyond market competition, irreversibility due to path-dependence, and the evolutionary advantages of a diversity of policy experiments in regions and countries are largely neglected or downplayed (see Section 6). Resource economics, dealing among others with renewable resources such as fisheries and forestry (Johansson and Löfgren, 1985; Clark, 1990), tends to search for optimal exploitation without taking into account evolutionary or selection effects of resource exploitation. Examples of relevant selection pressure due to resource use are maze size and season in fisheries (selection for small fish) and the use of pesticides in agriculture (selection for pest resistance). Neither does mainstream resource economics give much attention to the evolution of norms, for example, through local interaction of resource users (see Section 3). Environmental macroeconomics, in particular the extension of growth theory with environmental and resource factors to address sustainability issues (Toman et al., 1995), does not take the heterogeneity of firms and technologies into account as does evolutionary (differential) growth theory. In addition, it does not allow for much policy detail in terms of innovations, selection environment and lock-in. Extending evolutionary growth theories with environmental and resource variables, as well as applying coevolutionary theory to deal with long-run interaction of resources, behavior, institutions and technologies, might provide a response to deal with these shortcomings (see Section 4). Economic valuation and evaluation assume perfectly rational and selfish agents that are individually efficient (Johansson, 1987; Freeman, 1993; Hanley and Spash, 1993). Evolutionary insights, however, underpin that individuals are boundedly rational as well as otherregarding, explaining such phenomena as 'protest bidders', 'warm glow' and 'altruism' (Andreoni, 1990). The previous list should not be taken as an indication that mainstream environmental and resource economics is completely on the wrong track. However, it has its limits and may provide only partial and proximate insights in particular cases.

Although not explicitly evolutionary, a logical starting point for an examination of the evolutionary content of environmental economics is the seminal work of Nicolas GeorgescuRoegen (1971), who received his training in economics at Harvard under Joseph Schumpeter. The depth, rigor and fundamental nature of this work in ecological economics is comparable with that of Nelson and Winter (1982) in evolutionary economics, and represents a uniquely personal combination of views on energy economics (implications of thermodynamics), fundamental criticism on neoclassical economics, and philosophy of science (epistemology). It has stimulated study of the relationship between thermodynamics, economics and growth (Ecological Economics, special issue, 1997). Especially the so-called 'fourth law of thermodynamics', that is, 
limits to recycling have been the subject of much debate (Bianciardi et al., 1993). Together with Kenneth Boulding and Herman Daly, Georgescu-Roegen may be considered as one of the 'economic' founders of ecological economics, as he presented the notion of exosomatic instruments as an almost natural extension of endosomatic capabilities of humans - i.e. those which are part of the human body. He regarded human development (evolution) as the result of innovating in the exosomatic sphere.

Of all economists, Boulding $(1978,1981)$ is the one who has most clearly and consistently emphasized the analogy between ecology, evolutionary biology and economics, focusing on concepts such as homeostasis and population, as well as the distinction between genotype and phenotype. Norgaard (1984) was the first to discuss seriously the application of the concept of coevolution to the interaction between economic and natural systems. His main application has dealt with the coevolution of pests, pesticide and environmental policy in the USA (e.g., Norgaard, 1994). Nevertheless, his ideas have been criticized for not making a sharp distinction between interaction among subsystems (“co-dynamics”) and strict coevolution as interacting populations with internal diversity causing mutual selection pressure (Winder et al., 2005). Ayres (1994) is a very original synthesis in book form of evolutionary ideas about virtually any aspect of reality, starting with physics and chemistry, and culminating in an evolutionary treatment of economy and environment. Gowdy $(1994,1999)$ has stressed that the notion of macroevolution, interpreted as going beyond upscaling of microevolution (namely, 'downward causation'), might be relevant for thinking about economic evolution and macroeconomics, also in the context of sustainable development (see also van den Bergh and Gowdy, 2002). Faber and Proops (1990) have combined elements of the neo-Austrian approach - with its emphasis on the temporal and roundabout features of economic processes - and evolutionary thinking. Their approach very much continues the analogy of the distinction between genotype and phenotype in a socioeconomic realm (as per Boulding). Munro (1997) has offered a first rigorous model analysis of a net present value maximisation of agricultural crop cultivation when pesticide use causes selective pressure on the genetic composition of a pest population. This in fact combines neoclassical and evolutionary economic elements. Sethi and Somanathan (1996) and others have considered the endogenous character of norms in a common pool resource context using evolutionary game theory. The interest in evolutionary analysis of common dilemmas relating to renewable resources is indeed steadily increasing (Janssen, 2002; Janssen and Ostrom, 2005; Noailly, 2006). One version of the famous spatial evolutionary "Sugarscape" model of Epstein and Axtell (1996) incorporates a renewable resource (sugar) as well as pollution. More sugar allows accumulation of reserves, which contributes to survival, while more pollution is an 
incentive to move to other locations. Common and Neuman (2005) extend this model to address the impact of irreversibility in resource exhaustion. They find that history matters more than in the original Sugarscape world without irreversibility. Moreover, precautionary behavior (a 'safe minimum standard') is effective even when compliance is imperfect (though above a certain minimum). Finally, the attention to biodiversity loss evidently includes attention for geneticevolutionary aspects as well (starting with Weitzman, 1993). Some of the before mentioned studies are discussed in more detail in subsequent sections.

Table 1 tries to compare schematically evolutionary economics with mainstream environmental economics and (heterodox) ecological economics. Even if there is overlap between any two of the three fields, it is clear that ecological economics is less distant from evolutionary economics than is mainstream environmental economics. Ecological economics is indeed so pluralistic that it keeps the door wide open to evolutionary approaches, and now and then makes explicit use of evolutionary theory and methods. Evolutionary game theory is more popular in traditional environmental economics, much in line with its status in mainstream economics.

Table 1. Differences in emphasis between evolutionary, ecological and mainstream environmental and resource economics

\begin{tabular}{lll}
\hline Evolutionary economics & Ecological Economics & Environmental Economics \\
\hline Evolutionary potential & Optimal scale & Optimal allocation \\
Agent, technique, product diversity & Biodiversity & Representative agents \\
Innovation - recombination/mutation & Divergent views on innovation & Optimal R\&D \\
Fitness & Equity (intra/intergenerational) & Efficiency, cost-effectiveness \\
Evolutionary stability & Resilience & Sustainable macro growth \\
Adaptive limits & Limits to growth & Growth of limits \\
Path-dependence & Ecological irreversibility & Economic irreversibility \\
Varying time scales & Medium/long run & Short/medium run \\
Population/distribution indicators & Physical and biological indicators & Monetary indicators \\
Bounded rationality and selection & Myopic behaviour & Rational behaviour \\
Functional morality (fitness) & Environmental ethics & Utilitarianism \\
Adaptive individuals and systems & Causal processes & Equilibrium, comparative
\end{tabular}

Source: adapted from van den Bergh (2004).

\section{Resource use and ecosystem management}

Both ecological and environmental economics deal with ecosystem and resource management issues. This frequently involves paying attention to evolutionary dimensions, both in genetic and 
non-genetic terms. The dynamics of ecosystems and natural resources involves reversible as well as irreversible dynamics. The reversible dynamics relate to population growth and ecosystem succession, while the irreversible changes are partly the result of evolutionary changes, in the short run especially covering selection processes. Irreversibility also relates to systems being able to move to alternate equilibria. An important ecological notion in this context is 'resilience', a sort of extended stability concept. There are two alternative interpretations: (i) the time necessary for a disturbed system to return to its original state (Pimm, 1984); and (ii) the amount of disturbance that a system can absorb before moving to another state (Holling, 1973, 1986). In line with the latter interpretation, resilience has been phrased "Holling sustainability" at the ecosystem level in ecological economics, as opposed to "Solow-Hartwick sustainability" at the macroeconomic level in environmental economics (Common and Perrings, 1992). This distinction between conceptual approaches to sustainable development is in line with ecological economics devoting relatively much attention to ecosystem dimensions of sustainability, versus environmental economics emphasizing determinism and coarse long-term macro patterns (using macro growth theory extended with environment and resources).

Some authors have tried to find analogies of resilience in socio-economic systems. This addresses, among others, the negative impact of bureaucracy on resilience, the comparison of social and market economy systems, and the shortcomings of policies aimed at tight control and optimal trajectories rather than experiments, diversity, flexibility and adaptability (see Levin et al. 1998; Gunderson and Holling, 2002). The analysis of resilience is a useful alternative approach when traditional policy theory fails. Walker et al. (2002) mention a number of reasons for this to happen. The most important ones are that systems - economies or interactive economicenvironmental systems - contain thresholds, exhibit hysteresis and show irreversible change. In traditional, neoclassical economics' terminology this means that systems are not convex. Whereas within traditional economics this has been approached with nonlinear models providing aggregate descriptions of systems (Mäler et al., 2003), evolutionary approaches might shed light on the underlying microlevel mechanisms involved.

Janssen (2001) and Allen (2001) adopt the analogy of an immune system to understand the way in which resilience of economic-environmental systems can be maintained in the face of external perturbations. Both types of system are hierarchical and complex, based on internally diverse components that operate individually (agents) and are involved in local interactions, and both include some type of selection. System resilience fails when an external influence is too novel, too fast, or too abundant (external factors), or when the system has invested too much in the wrong defense or lacks internal diversity (internal factors). Ecological resilience depends on 
the way in which systems are self-organized, or how they are managed. Management is negatively seen as any action that reduces natural variability. Allen (2001) concludes: "As with the human body, we must be wary of too much remedial intervention in the face of invasions. Overmedicating trivial illnesses leads to hardier pathogens and weakened populations of 'friendly' bacteria, leaving the body more vulnerable to progressively worse infections. In ecosystems, too much intervention can have an analogous effect.”

Resilience is often linked to biodiversity. There is much support for the idea that in general more diversity enhances the stability of systems (Holling et al., 1994). However, biodiversity is lost at an unprecedented rate. The most influential factors have been the occupation and fragmentation of space, the harvesting of biotic resources, the introduction of exotic species in ecosystems, and the emission of toxic substances. Not surprisingly, research on biodiversity loss and conservation in environmental economics has taken a swift flight (Swanson, 1994; Perrings et al., 1995; Weitzman, 1993, 1998; Brock and Xepapadeas, 2003). Many of these studies struggle with the complexity arising from genetic and sometimes other types of diversity, at the level of species, ecosystems and functions. Weitzman (1998) is the most influential study here. He studied the problem of protecting biodiversity under a limited budget constraint and thus derived a concrete criterion for setting priorities among biodiversity-protecting projects. This is based on the assumption that the loss of biodiversity due to the extinction of a species is exactly equivalent to the distinctiveness of that species, defined as the genetic distance between species. Uncertainty of extinction is introduced by defining exogenous, known - possibly subjective probabilities of survival of all species. The resulting criterion implies, for instance, that in a situation with two species and identical costs of protecting each species, identical utility and identical changes in survival probabilities, it is optimal to protect the species that is the most distinctive. Baumgärtner (2004) and van der Heide et al. (2005), however, show that distinct policy advice may result when in addition to genetic diversity ecological relationships are taken into account.

An important type of loss of biodiversity that directly feeds back to human resource use on ecosystems and populations of living organisms is the selective pressure caused by managing and harvesting practices. The general nature of the problem is that resource harvesting not only affects the quantity of the resource but also its quality or composition in genetic terms. Examples can be found in agriculture (use of pesticides, herbicides, fungicides; monocultures), fisheries (maze size, season of fishing), ecosystem management (groundwater control, fire protection), and health care (use of antibiotics). A number of economic and management issues are relevant here (Munro, 1997). Since the rate of mutation is low, selection of resistant individuals in a population 
is the main evolutionary mechanism to be addressed. Resistance usually has a (small) cost, otherwise the resistant individuals would be well represented even without selection pressure from pesticides and the like. In other words, the resistant individual is relatively susceptible to other stress or selection factors. Withdrawal of the selection pressure (e.g., removing pesticides) will then usually lead to a decline in the proportion of resistant individuals in the population. Nevertheless, selection pressure often reduces (bio)diversity in the population irrevocably. This may be regarded as an intertemporal externality. A relevant question, then, is whether the costs of overcoming resistance are increasing over time. Due to cross-resistance (i.e. resistance to one type of insecticide creating resistance to others), such costs often turn out to increase fairly rapidly, in spite of learning effects (notably, developing new antibiotics). Moreover, a renewed introduction of the selection pressure will very quickly achieve widespread resistance due to the relatively large proportion of resistance-affecting genes in the population. The risk of crossresistance depends on the type of (metabolic/biological/chemical) mechanism through which individuals achieve resistance. This can include excretion of the unabsorbed insecticide, changes in behavior, or reduced penetration of the chemical in the body.

Munro (1997) deals with these various issues by extending the standard, general model of optimal use of a renewable resource (of which the optimal pesticide use model is a special case) with a negative intertemporal externality based on genetic selection. He illustrates this for an insecticide that raises the fitness of resistant insects relative to their susceptible competitors. The perspective can be that of an individual farmer or, more realistically, a policy maker trying to understand the optimal dosage of insecticide in a region. Some main insights obtained are as follows. The traditional planning solution may be considered to be myopic, as it does not anticipate evolution. Instead, optimization under perfect foresight about evolutionary consequences of insecticide use gives the fully optimal plan. Comparison of myopic and fully optimal plans shows that, under the latter, the size of the pest population is lower, while the proportion of susceptible individuals is higher. For a higher discount rate, the optimal pesticide use will be higher as well, so that resistance will increase. As a corollary, under myopia, investment in R\&D on new pesticides will be relatively high.

Van der Voet et al. (2000) offer a qualitative analysis of the evolutionary consequences of human dominance in the biosphere at a somewhat more general level. They argue that impacts are very heterogeneous for different types of living organisms. In evolutionary terms, one can classify influences as changing the selection environment (predation, nutrients, habitat and chemical pollutants), introducing new mutations (exotic species, chemical pollutants), affecting spatial isolation (infrastructure), and influencing reproduction advantages (pesticides). Ultimate 
consequences are extinction or influences on speciation, thus affecting the direction of natural evolution. Predators and prey species are especially sensitive to this, for different reasons. Predators live in small numbers, follow an ecological K-strategy, require a large habitat, and often have no or a relatively low (or even negative) economic value. They are especially sensitive to land use, toxic substances (concentration in food chain) and hunting. Due to a low reproduction rate, they are not very adaptable. Prey have a positive economic value, and remain part of a preagricultural hunting culture. Harvesting pressure is the most serious threat, especially for fish populations. Most prey species predated by humans have been domesticated; the last major group of "free" prey species, i.e. fish populations, are now being increasingly domesticated as well (fish farms). This might be considered as a sort of final stage in cultural-natural coevolution. Current trends suggest that predators and prey species loose ground, pets are little affected, while pests gain.

The previous approach offers a useful categorization to analyze the evolutionary consequences of resource exploitation activities from an economic perspective. In addition, the study of multispecies systems in resource economics (Hoekstra and van den Bergh, 2005) might be extended with evolutionary elements to consider the indirect impacts of, for example, fishing or harvesting one species upon another species (or population) through a one-directional or even mutual (coevolutionary) selection mechanism. This would, in fact, mean a shift from 'mechanistic, stock sustainability' to 'evolutionary, ecological sustainability', which provides a more satisfactory though analytically more difficult approach to sustainability analysis of resource use and management.

Since Hardin (1968), much attention in environmental economics has been given to the risk of overexploitation of common-pool resources (Bromley, 1992; Ostrom, 1990). Although common property is often confused with open access, where exploitation is more likely, in common property resources the risk is serious, as it depends very much on the type of common property regime that is active, and may therefore differ from situation to situation. An important question is whether resource conflicts and overuse require as a response strict regulatory policies set by higher level governments, or that instead one should rely on endogenous formation of use regimes. An evolutionary perspective has been used to analyze the latter, based on the idea that such regimes need to receive sufficient support from the individuals participating, or in other words, that a single norm evolves (Axelrod, 1986). An important finding is that externally imposed rules and monitoring can reduce and destabilize co-operation or even completely destroy it (Ostrom, 2000). Stimulating norms through communication may then be more desirable. This is certainly the case when hierarchical monitoring is imperfect. Instability in the evolutionary 
equilibrium can arise when certain parameters change, for instance, when sanctions decline, harvesting technology becomes more productive (technical progress), or the price of the resource increases. Other risks to evolved norms are migration, external economic and political disturbances, and natural disasters influencing the resource. These issues have been examined using a wide range of approaches, such as empirical field studies and laboratory experiments (Martin, 1989/1992). Despite much theoretical and empirical research, not all aspects of this selforganisation process are fully understood. For instance, the effect of group size is still not very clear.

Studies combining economic evolution and renewable resource dynamics in the context of common pool resources are rare. Noailly et al. (2003) present an analytical analysis of the basic problem. They step away from the traditional assumption of rational harvesters and assume instead a distribution of harvesting strategies that change according to replicator dynamics. The interaction of evolutionary and resource dynamics leads to the result that both strategies may survive in the long run. A similar but somewhat more complicated model is Sethi and Somanathan (1996). This is the first one that combines two dynamic relationships: evolutionary (replicator) dynamics and renewable resource dynamics. The evolutionary model is set up as a two-stage game: resource use strategy, punish or not; punishment is costly. There are three strategies: defecting (high effort); enforcing (low effort, sanctioning of defectors); and cooperating (low effort, no sanctioning of defectors). The profits under each strategy are variable and depend on the distribution of strategies. Dynamics following from the selection of highest pay-off strategies are modelled as replicator dynamics. The result is really only pure equilibria: defecting or restraint (cooperating or enforcing). In other words, in the end, nobody or everybody cooperates. The game can be seen as a mix of prisoner dilemma and coordination games. Once a defector equilibrium is reached, recovery of cooperative behavior is difficult. Note, however, that this is not the case in spatial interaction games, in which the spatial structure of agents (e.g., local interactions) is explicitly modelled (Noailly et al., 2006). This gives rise to clusters or zones of cooperation protected by enforcers against intruders, i.e. defectors.

The multi-agent evolutionary models that use a spatial disaggregate (grid, cellular automata, or network) structure can be quite easily built on ecological foundations, as spatial models are common in applied ecological modelling (Grimm, 1999; Janssen and Ostrom, 2005). Generally, the integration of economics and ecology has been hampered by the lack of space in economic theories and models. Whereas many ecological and hydrological processes are amenable for a grid-based description, most economic processes operate at higher scales. This explains, for instance, why a method such as 'cellular automata' is more common in landscape ecology than in 
spatial economics. Cellular automata were originally used to model process-based predator-prey interactions, changes in surface water quality, and fire propagation problems. They allow for an explicitly spatial process approach. Whereas, in physical and biological systems, such immediate influences in space dominate, this is not the case in social and economic systems. Here, 'spaceless' information (e.g., in the form of books, databases, web sites) plays an important role in individual and public decisions. Moreover, many spatial interactions in an economic context extend beyond the scope of 'neighboring cells' - witness international trade and globalization. The application of cellular automata in social science thus seems very limited, unless generalisations and extensions are used - and further developed - that allow for direct interactions between non-bordering cells (Couclelis, 1985).

\section{Evolutionary growth, coevolution and environmental resources}

This section will illustrate the usefulness of evolutionary thinking for understanding long term growth and development in relation to environment and resources. This relationship has received much attention from environmental economists. The so-called 'growth debate' is relevant here where growth commonly refers to a rise in gross domestic product (GDP). This debate can be characterized by three core questions (van den Bergh and de Mooij, 1999): (i) Is growth desirable: are there social limits? (ii) Is growth feasible: are there environmental or physical limits? (iii) Can growth be controlled or steered: are there governance limits? By simply checking all combinations of yes/no answers to these questions, one can identify eight positions in the 'growth debate'. These questions have been largely addressed using traditional growth theory. Purely theoretical analysis has focused on resources and environment as added variables in standard growth models (Dasgupta and Heal, 1979). More recently, climate change research is an area where (optimal) growth models have been actually "applied” (Nordhaus, 1994), leading to considerable criticism (e.g., Azar 1998; van den Bergh, 2004).

Evolutionary economics offers an alternative, which is differential growth. This reflects a change in the frequencies of all possible individual (firm) characteristics. An important feature of evolutionary growth theory is the lack of an aggregate production function (van den Bergh and Gowdy, 2002). Instead, a micro-approach is adopted in which a population of heterogeneous firms is described. Nelson and Winter (1982: Chapter 9) developed the first formal evolutionary model of economic growth. This model describes changes in the state of a sector as following a Markov process with time dependent probabilities, which depend on search, imitation, investments, entry and selection. Search is local, implying small improvements and staying close to the present production technique. Imitation can focus on either the average or the best practice. 
Other formal evolutionary models of growth have been proposed by Conlisk (1989) and Silverberg et al. (1988). Conlisk derives a growth rate analytically as being dependent on the rate of diffusion of innovations and the size of innovations as indicated by the standard error of the productivity probability distribution. Silverberg et al. have proposed an evolutionary growth model in which new capital results from profit accumulation, where profit is redistributed so that relatively profitable types of capital accumulate relatively fast. This can be regarded as a combination of selection and a growing 'population of technologies' through accumulation. Firms can employ two strategies for innovation: mutation or imitation. Innovation follows a Poisson process, while the probability of imitation depends on the gap between the firms' own profit rate and the maximum profit rate in the population. This follows the general model of innovation and imitation as developed by Iwai (1984).

Based on such approaches, two main lines of research could be developed as an alternative to neoclassical growth theory in environmental economics. First, such differential growth models could be extended with environment and resource variables to study the impact of alternative (evolutionary) assumptions (bounded rationality, non-representative agents, selection, innovation) as well as different types of policies, notably those relating to environmental regulation, investment in $R \& D$, and the selection environment. Second, extensions of technological innovation models with environmental resource considerations might be used to study the long-run implications of innovation strategies, major innovations, increasing returns, and long waves, as well as the impact of resource scarcity and environmental regulation on innovation opportunities and tempo (van den Bergh, 2005). In these latter type of models, innovation, selection, path-dependence and lock-in rather than capital accumulation would play the central role. Saint-Jean (2006) notes that attention needs to be given to two specific issues: evolutionary modelling of supply-demand chains, and of technological complementarities, especially with an eye to 'hybridization' of technologies. Obtained insights may inform policy aimed at large-scale transitions, such as from fossil fuels to renewable energy: intermediate phases might indeed involve hybrid technologies, such as mixing fossil and biomass fuels, or combining fuel cells running on hydrogen with combustion engines in 'hybrid cars'. Policies lessons might further involve insights about which instruments (regulation through environmental levies or innovation incentives such as subsidies) to use in which part of the innovation cycle or stages - research, development, demonstration and deployment.

In order to put economic growth in an accurate historical context, one needs to address the interaction between economies and environmental resources. Few complete models are available for this purpose. The notion of coevolution may be useful here. It integrates elements 
from evolutionary biology and ecology. The strict meaning of coevolution is that two populations with internal diversity interact in such a way that they influence each others selection environment, so that their evolutionary patterns are coupled (van den Bergh and Stagl, 2003). Surprisingly few formal models have been developed to capture this idea, but they show that the level of complexity and irregular dynamics characterized by extreme sensitivity is very different from that of traditional mechanistic non-evolutionary interaction ('co-dynamics') between subsystems (Noailly, 2003, chapter 6). Moreover, coevolution can take different forms (Durham, 1991):

1. Genetic mediation: Genetic changes influence cultural evolution.

2. Cultural mediation: Cultural changes influence genetic evolution.

3. Enhancement: Cultural change reinforces natural evolution.

4. Opposition: Cultural change opposes biological evolution.

Although these coevolutionary mechanisms are phrased in terms of gene-culture relations, they can be generalized to other types of coevolution, for example, technological-institutional or technological-behavioral type of interrelations. The mutual, long-run impact of economic development, natural resources and environment can be handled by using these coevolutionary mechanisms to construct a model that describes the various interactions between resources, behavior (agent strategies), institutions and technologies. The latter three entities can then best be cast in terms of populations characterized by internal heterogeneity. In a resulting model, not only resources cause selection effects on these populations but also the populations exert selection pressure on each other, through one of the four general modes described above.

Horan et al. (2005) have used economic models to examine why the competition for food between Neanderthalers and early Homo sapiens worked out positively for the latter and led to extinction of the earlier. The extinction of the Neanderthaler is often atttibuted to a better evolutionary adaptation of Homo sapiens to its natural environment. The question is, however, what determined this adaptation. The authors suggest that Homo sapiens was less capable of competing through physical force - in terms of hunting, gathering food and even fighting - which stimulated the development of specialization and trade. This allowed more efficient handling of various tasks, such as hunting, food gathering, producing clothes and constructing shelter, with positive impacts on survival and reproduction. This point was earlier made by Ofek (2001), who makes explicit use of evolutionary arguments. Neanderthalers lived in smaller groups and there is no evidence that they undertook some form of trade. Specialization also may have allowed Homo sapiens to outcompete physically stronger Neanderthalers in hunting, since only the most capable 
people might have been given the task to hunt, whereas less able hunters would perform other tasks in the small economy.

Diamond (1997) summarizes the large literature that has tried to support the theory that the availability of animal and plant species stimulated early domestication and thus agriculture and settlements. He notes that sufficient diversity of agricultural experimentation was only possible on continents with the major axis being east-west oriented, as this would allow for a spread of agricultural technologies among regions with similar climates. This he considers as an important reason for the early 'economic success' of Eurasia. Diamond's theory thus explicitly relates early economic development to geographical and resource factors. His ideas are consistent with theories of spatial diffusion of technological innovations.

With regard to the more recent period of sustained growth, Galor and Moav (2002, p1) argue that: “... the struggle for survival that had characterized most of human existence generated an evolutionary advantage to human traits that were complementary to the growth process, triggering the take-off from an epoch of stagnation to sustained economic growth.” This view fits in the "enhancement mode" of Durham's coevolution discussed above. The hypothesis is that selection (and possibly recombination) effects may have changed the distribution of certain parental care characteristics, notably the trade-off between quantity of offspring and quality of parental care. In modern economic growth jargon, such quality improvements can be regarded as an early or even ancient type of investment in human capital. In particular, the gradual emergence of the smaller family since the rise of agriculture may have played an important role in this. Hitherto, larger groups, such as tribes built around one or more extended families, had a dominant influence on human evolution. Galor and Moav argue that human organization by way of smaller families fostered a strategy that focused relatively much attention on parental investment in quality of offspring, such as education. This, together with a sufficiently large size of the communicating human population, led, through technological innovation, to the essential impetus for the take-off of the Industrial Revolution. In other words, they propose a kind of "endogenous evolutionary theory" of the Industrial Revolution. The selection pressure was effective during the preceding "Malthusian era" because the majority of people were living at a subsistence consumption level.

Wilkinson (1973) develops an ecological theory of economic development that aims to link the Industrial Revolution to natural resource factors (see also Common, 1988). He starts by noting that agriculture and iron smelting used large amounts of timber for energy purposes, which gave rise to a significant loss of forest cover in England. The resulting shortage and related high price of wood stimulated the use of coal. In an early phase, this focused on coal mining in strips at the 
surface. Later on, deep mines were explored, which required the pumping out of groundwater. This allowed for the first large scale application of the steam engine. Widespread use of it gave rise to various refinements as well as competing designs. In a next phase, spin-offs to other sectors occurred, especially the textile industry and transport through ships and trains led by steam locomotives.

Technological change is obviously important in understanding the long term relationship between the economy and the environment. Evolutionary models of technological innovation have hardly been applied to address either the impact of policy on environmental technology or the role of such technology in long term sustainable development. For example, the surveys by Jaffe et al. (2001) and Löschel (2002) do not pay any attention to evolutionary approaches. Faber and Proops (1990) may be considered as an exception. They propose a neo-Austrian approach with evolutionary elements, to emphasize the role of time. They allow for irreversibility of changes in the sector structure of the economy, for uncertainty and novelty, and for a teleological sequence of production activities. The long term relation between environment, technology and development is then characterized by three elements:

- The use of non-renewable natural resources is irreversible in time, so that a technology based on it must ultimately cease to be viable.

- Inventions and subsequent innovations lead to both more efficient use of presently used resources and substitution to resources previously not used.

- Innovation requires that a certain stock of capital goods with certain characteristics is built up.

Based on these foundations a multisector model is constructed with a production side formulated in terms of activity analysis. The model is capable of replicating transitions from a situation with a simple to more complex or roundabout production activities. Roundabout activities use multiple technologies. The model is used to simulate economic and environmental history from a preindustrial agricultural society to an industrial society, using fossil fuels and capital. To some extent, this may be considered as a formal elaboration of the earlier ideas by Wilkinson mentioned above.

\section{Evolutionary progress}

This section addresses the first question in the growth debate, namely whether growth means progress from an evolutionary perspective. One cannot assume that economic growth defined as GDP growth automatically implies progress simply because GDP increases. The reason is that the 
GDP is not a robust indicator of social welfare (van den Bergh, 2006). Progress is in fact a subjective concept that can be defined or interpreted in many ways. An original way to illustrate this, taking into account that the economy is an evolutionary system, is to consider criteria that have been proposed to identify evolutionary progress (e.g., Gowdy 1994, Chapter 8; Gould, 1988):

- Increasing diversity: As diversity holds the key to genetic and therefore phenotypic adaptation to changing circumstances, it is often regarded as reflecting evolutionary potential. Economic diversity might foster adaptive capacity of humans and economies in the face of environmental changes (e.g., climate change).

- Increasing complexity: This can apply to morphological structure, or to the number of components or functions. Potts (2000) generalizes this in terms of an increase in the number of connections as well as the levels of nesting of such connections. Emergence of new levels might be interpreted as progress.

- Extended division of labor: This can be observed within both natural and social-economic evolution: specialized cells in multicellar organisms, organs, ants in colonies, social organization, complex production activities. This was recognized by both Darwin and Spencer, and provides a link with economics that goes back as far as Adam Smith.

- New ways of transmitting information: Living and nonliving complex dynamic systems depend on information exchange. This includes molecular interactions within and between cells, nerves, blood vessels, the lymph system, and chemical substances such as hormones, senses (sound, smell, vision), and social interaction through symbols and language. In the economy, communication has gone through various phases as well: walking, horse, carriage, ship, train, car and plane, and telegraph, phone, fax, and email and Internet. An important result has been a steady growth of the communicating population, interpreted as "the world is getting smaller”.

- Population growth: From an evolutionary perspective, a species is successful if it wins over competitors, meaning dominance in niches or even ecosystems and control of its direct environment. In addition, emergent properties of systems - i.e. new levels of reality - seem to be closely related to the size of groups. In other words, a minimum size is needed for a new level to arise. Think of brain cells in relation to consciousness, or ants in relation to ant colonies.

- Adaptation: Dawkins (1982) regards the best evolutionary progress criterion to be how well a species or system is adapted to its environment. He acknowledges that this often goes along with increasing complexity. 
From an environmental perspective, one additional criterion should not be left unmentioned. This may be formulated as increasing efficiency of energy capture and transformation. Both in economic and biological systems, evolution may be related to energy processes such as creation, transmission and stocking of energy (or more correctly 'exergy', which denotes a nonconserved entity). This has received most systematic attention in the recent literature on self-organization and complexity (O’Connor 1991, Buenstorf 2000). From an ecological-evolutionary perspective, a rise in energy efficiency means less scarcity and less selection pressure, thus creating opportunities for (population) growth. The important insight here is that evolutionary systems that can tap a larger source of external exergy are able to do more work, and maintain a more complex structure. This is consistent with the immense impact the large-scale access to fossil fuel resources has had on economic activity, structure and growth following the Industrial Revolution.

A specific theory proposed by Schneider and Kay (1994) provides additional suggestions for the relationship between energy and evolutionary progress. It states that life (ontogeny) and evolution (phylogeny) involve processes that are manifestations of the second law of thermodynamics. Open systems tend to destruct energy (exergy or entropy) gradients, by energy degradation (reducing exergy value) and dissipation (exported or transferred exergy). Systems evolve into more complex arrangements so as to improve degradation and dissipation, and thus destruct energy gradients. This phenomena finds empirical support in the fact that more complex or developed ecosystems - in the succession towards a climax - tend to be 'cooler', i.e. their radiated energy has a lower temperature. This means that they are better degraders of energy than less developed ecosystems. Based on this recognition, one can identify illegal waste dumps in natural areas using remote sensing techniques. The improved ecosystem capacity for energy degradation goes along with more energy capture, more cycling of energy and material, a more complex trophic structure, more biomass, and more diversity of species. All these elements fit the idea that pathways are created to funnel, 'recycle' and increase 'residence of energy' (and materials) so that any exergy can be maximally degraded. Schneider and Kay illustrate these ideas with a comparison of "stressed" and "control" marshes: stress leads, among others, to less respiration and a less complex food web, i.e. fewer channels for energy degradation.

According to Maynard Smith and Szathmáry (1995, p4), "The notion of progress has a bad name among evolutionary biologists.” This is reflected by the fact that many professional biologists avoid any discussion of progress, and even use of the term, in their professional writings, even though some of them have turned out to be pronounced proponents of progress in their popular science writings. Maynard Smith and Szathmáry suggest that the history of life is 
better depicted as a branching tree rather than progress on a linear scale. ${ }^{1}$ Many species have changed little over the course of hundreds of millions of years. There are several reasons why evolution does not necessarily give rise to progress (extending Campbell 1996, p433):

1. The most important reason is that selection is a local search process, which leads at best to a local optimum (not "survival of the fittest”, as first coined by Herbert Spencer, but survival of the fitter or relatively fit).

2. Adaptations are often compromises between different objectives, being stimulated by a multitude of selection forces. This suggests that evolution is better regarded as multi-criteria evaluation than as single-objective optimization.

3. Organisms are locked into historical constraints. In biology, this has been referred to as "bauplan limits” or "development constraint” (Gould and Lewontin 1979) or phylogenetic inertia (Wilson 1975, p20). In economics, it is treated under the headings of increasing returns to scale, path-dependence and lock-in (Arthur 1989). In organization theory, it has been called "structural inertia” and “imprinting” (Hannan and Freeman 1989, p70 and p205, respectively).

4. Not all evolution is adaptive microevolution: randomness, genetic (molecular) drift, coincidental founder effects, etc. play an important role. In addition, macroevolution creates boundary conditions for adaptation and may destroy outcomes of microevolution, in a way as to set back time ('initialize').

5. Selection can only 'capture' variations that exist; the process of creation of variation is limited and largely random.

6. Agents explore only a minor range or subset of the opportunity space, which is reflected by the notion of bounded rationality.

7. Coevolution means that the environment is not constant and exogenous to the individual species' evolution, but influenced by it. Coevolution means adaptation to an adaptive environment. All straightforward notions of static or dynamic optimization are lost, since the boundary conditions in a constrained optimization formulation of evolution are not even known. Coevolution also has historical, path-dependent features. It can be cast in the adaptive

\footnotetext{
${ }^{1}$ Nevertheless, certain authors, notably Conway Morris (2003) and Dawkins (1997), maintain that the broad strokes of evolution are almost inevitable, including the emergence of intelligent organisms such as humans. This can be called 'convergence': “... what is possible has usually been arrived at multiple times, meaning that the emergence of the various biological properties is effectively inevitable..” (Conway Morris, 2003, preface). He adds the provision that, partly due to limited evolutionary time, the number of evolutionary end points (possible biological structures) is limited.
} 
landscape metaphor (Kauffman, 1993), in which case the landscape becomes something like a "... choppy sea rather than something forged in granite. In which case there would be no real progress, for as soon as one climbed a peak it would collapse beneath one.” (Ruse 1999, p118).

Sen (1993) further notes that evolution as improving species does not imply improving the welfare or quality-of-life of each individual organism. Fitness is not a useful criterion for progress in general, even though the evolution of a species into one that is more efficient in food gathering, moves faster (running, swimming, flying), or is more effective in performing certain functions, can usually be regarded in terms of fitness increase. The reason is simply that a higher fitness and survival do not necessarily imply a happier or more pleasant life. In fact, evolutionary models often show that inequality arises again and again in evolutionary systems, suggesting that structurally at least part of a population is relatively unhappy (e.g., Epstein and Axtell, 1996).

The latter is strengthened by evolutionary theory and psychology as they have been invoked to support criticism on GDP growth as a social objective. At the level of psychology, the distinction between basic and higher needs (Maslow's pyramid, or lexicographic preferences) is relevant. Once basic needs are satisfied, one is in the realm of the higher needs. With regard to the latter, individual income and consumption cannot be seen separately from other individuals in a relevant social environment ('peer group'). The notion of relative or context-dependent wellbeing has been proposed to address this (Tversky and Simonson, 2000). This notion is characterised by a comparison and rivalry with others. This explains the striving for "conspicuous consumption” (Veblen, 1998), "positional goods" (Hirsch, 1976) and "status goods” (Howarth and Brekke, 2003). Evolutionary biology has discovered that the function of conspicuous and extravagant traits of animals is to attract sexual partners and to repel sexual competitors. Humans are no exception, and it is no surprise that rivalry consumption is found in all times and cultures (Buss, 1989). Nevertheless, it has become a very serious problem as it now relates to large-scale environmental impacts, as a result of unprecedented large numbers of consumers, high living standards and pollutive production techniques. Biologists refer to the fact that only individuals with a relatively high physical or mental quality can bear the cost of extravagance as the "handicap principle”. That one can waste means to seemingly useless - but certainly not 'fitnessless' or 'function-less' - consumption, gives a signal of superiority, which increases one’s social status. In turn, the probability of finding a suitable sexual partner and thus fitness increase. Sexual selection has fixed this behavior in our genes (psychologists call it 'automatic'), which explains why even individuals who already have a partner still seek status improvements. 
Relative welfare and rivalry consumption are closely related to (endogenous) changes in preferences. Many of these are formed or at least influenced by media, steered by commercial, private (business) interests. The rivalry feelings are greatly misused for this purpose, in the direction of both adults and children. Income rises usually go along with new products and changes in preferences. No one, however, guarantees that the creation of new preferences contributes to happier lives. Therefore, the rivalry has been negatively characterized as reflecting a "rat race" and "affluenza virus". It resembles the "Red Queen hypothesis" in evolutionary theory: repeated selection for fitness so as not to be taken over by others (Strickberger 1996, p511). The phenomenon of relative welfare and rivalry in consumption means that a rise in relative income can increase the well-being of a particular individual, while being neutral or negative for social welfare. The reason is simple: improvements in relative income and welfare come down to a zero-sum game - one person loses what another gains (Layard, 2005).

Concluding, evolution has some elements of directionality and progress. Nevertheless, evolution certainly is not identical with continuous progress. Furthermore, much of what is presented as progress by optimists often possesses mixed blessings.

\section{Bounded rationality, evolution and environmental policy}

The previous sections have already provided many policy suggestions. In this section, we will offer some additional ideas coming from the application of evolutionary economics.

An important fundamental starting point for policy thinking from an evolutionary angle is that environmental problems often go along with a loss of diversity of options, not only with regard to biodiversity but also in terms of cultural and economic diversity. Loss of the latter type of diversity occurs through the diffusion of dominant lifestyles, technologies, institutions (formal markets, regulatory models) and production methods (e.g., in agriculture). One might see this as an extreme outcome of repeated selection which sometimes results in lock-in. Environmentally relevant 'lock-ins' can be found in many places. The most significant example is the complete dependence of modern economies on fossil fuels, which can be traced back to the Industrial Revolution, in particular to the invention and diffusion of engines that combust fossil fuels (coal, oil, gas), and the strong dependence of electricity generation as well as modern transport systems on such engines.

From the perspective of path-dependence and lock-in, relevant questions are how regime shifts occur, how they can be stimulated, and how new lock-ins of inefficient or undesired technologies can be avoided. Preventing early lock-in requires a sort of portfolio investment. Unlocking of undesired structures and technologies - from an environmental or some social welfare 
perspective - cannot be realized by simply 'correcting prices', but requires also taking into account increasing returns on demand and supply sides, and (potential) learning curve effects. This has been referred to as transition policy (Elzen et al., 2004; van den Bergh et al., 2006a,b) and it requires additional policies, notably innovation policy. Examples are well known in the area of environmental policy. Setting a clear overall goal such as 'zero emissions' in California meets the requirement of reducing policy uncertainty. Creating semi-protected niches can work in stimulating renewable energy sources, notably solar energy based on photovoltaic cells. Other elements of a strategy to avoid lock-in or unlock include stimulating a diversity of $R \& D$, stimulate pathway and complementary technologies (e.g., electric batteries, fuel cells) (see Schwoon, 2006).

Rammel and van den Bergh (2003) emphasize that policy strategies should be aimed at increasing diversity and adaptive flexibility, and at reducing risk. Evolutionary potential will be stimulated through this. Such an approach can be operationalized through stimulating selfregulation (Section 3) and adaptive management, which is characterized by learning through experimentation (Walters, 1986), and can also involve elements of resilience management (Section 3). Maintaining and increasing diversity are key objectives here. This in fact may be regarded as an evolutionary perspective on the much-adhered-to precautionary principle. Costeffectiveness should not be given priority, as it can be counter-productive and focused too much on short run effects (van den Heuvel and van den Bergh, 2005). An alternative or complementary strategy is to create what Unruh (2002, p.323) calls "a countervailing critical mass or social consensus for policy action” through education of the general public. But at the same time he recognizes the difficulty of this due to the complexity and uncertainty of climate change. He suggests that providing information on extreme climate events (disasters) may create support for strict climate policies and changes in current institutions. This is supported by Janssen and de Vries (1998), who have incorporated evolutionary elements in climate modelling by allowing adaptive agents to change their behavioral strategies. These agents respond to persistent surprises in global climate, as represented by the global mean temperature of the atmosphere. The distribution of strategies changes according to a selection process modelled as a replicator equation. Agent fitness is a function of the difference between expected temperature change and actual temperature change. Climate surprises that cannot be made consistent with the initial perspective stimulate adaptations.

Implicit in the previous discussion is the suggestion that a fundamental question in the context of environmental policy is how to balance diversity and efficiency. This is especially true when addressing long-term issues related to stimulating a transition to sustainable (renewable) 
energy, transport and agricultural systems, which have all the features of lock-in. While from a short-term efficiency perspective fostering diversity is easily regarded as wastage, from a longterm perspective it represents potential evolutionary progress. A trade-off must be made between short and long-term efficiency, providing 'optimal diversity'. Economics has dealt with this problem through option value (Fisher, 2000) and real options theory (Dixit and Pindyck, 1994; Pindyck, 2000). However, these approaches treat diversity as exogenous and fixed. Evolutionary theories and models offer a better approach to examine the long-run value of diversity, as they treat diversity as changing, endogenous, and affecting as well as being affected by evolutionary system dynamics (i.e. selection, innovation and retention).

The traditional economic theory of environmental policy is the result of applying neoclassical welfare theory, which comes down to connecting a competitive equilibrium and a social welfare optimum (or, less ambitiously, Pareto efficient situation). Evolutionary systems based on bounded rationality, non-equilibrium and path-dependence offer a less optimistic view on policy, and imply that the normative part of neoclassical economics is based on partly incorrect assumptions. If, due to this, the correspondence between a market equilibrium and a social welfare optimum is lost, then inevitably the two fundamental theorems of welfare economics no longer hold. As a result, planning or market solutions cannot be guaranteed to deliver socially optimal outcomes.

From a bounded rationality perspective, various alternative views on environmental policy have been proposed. Roe (1996) uses "Girardian economics" to address pervasive uncertainty, which suggests mimetic behavior (imitation) to dominate, leading to reduced economic diversity of behavior, strategies, activities, ideas, products, etc. This model is applied to the problem of sustainable development (SD), which leads a number of insights: SD is a social convention which can stabilize decision-making under high uncertainty; reducing uncertainty can undo the trend of "undifferentiation" (homogeneity) due to imitation. Some specific elements of such a strategy are: buffer or decouple resource systems and their management from environmental uncertainty; encourage diversity, via evolution of more than one kind of SD for various cases or in different regions. This approach is very much in the spirit of evolutionary economics.

Penn (2003) argues that individual incentives are the most effective way of environmental policy. This seems to be consistent with the main policy message of environmental economics (Baumol and Oates, 1988), but Penn adds the provision that these incentives go beyond narrow economic, monetary interests. They should, for instance, also take social interactions (e.g., reputation effects) into account. This is consistent with findings of economic 
psychology and experimental economics, as well as of group selection theory (Bergstrom, 2002; Henrich, 2004). Group phenomena can be linked to a variety of social - non-selfish or otherregarding - preferences: reciprocal fairness, inequity aversion, pure altruism, altruistic punishment and spite or envy (Fehr and Fischbacher, 2002).

Against this background, Hausfather (2006) considers the well-known Coase theorem (Coase, 1960), which states that, in the presence of pollution, a socially optimal outcome may result through bargaining between polluter and victim, regardless of initial property rights (in the absence of transaction costs). He argues that this result may fail to occur when fairness norms and legal property rights are incongruent, since then altruistic punishment is likely. Kahneman et al. (1990), relating psychological property rights (equivalent with fairness norms) to endowment effects, show that the latter can explain why the willingness to accept the loss of environmental goods and services will be considerably higher than the willingness to pay for them. They also conclude that Coasian bargains are less likely when fairness norms and legal property rights are inconsistent. In view of this, it is not surprising that persistent conflicts rather than swift bargains are a common response to environmental externality problems (Martinez-Alier, 2005).

Various other aspects of bounded rationality have implications for environmental regulation (Kemp, 1997; van den Bergh et al., 2000 and 2006b; Brekke and Howarth, 2002). Evolutionary thought can help here in assessing fundamental, ultimate causes of environmentally relevant behavior. These may relate to our genetic constitution or to stable, culturally evolved institutions. Increasing our insight about these fundaments in turn will aid the formulation of effective and robust policy responses to environmental problems.

\section{Conclusions}

Over the past decades, economists have devoted many efforts to research on environmental and resource issues. This has given rise to an impressive body of knowledge known as environmental and resource economics, and more recently to the emergence of a multidisciplinary field known as ecological economics. Evolutionary economics could provide the necessary theoretical and methodological inputs to provide answers to a number of pressing problems in either field. This involves giving attention to themes such as the management of ecosystems subject to selection pressure, spatial modelling of self-organized local regulation in common pool resources, the impact of evolutionary growth on resources and environment, fundamental evaluation of progress from an evolutionary angle, and environmental policy inspired by evolutionary mechanisms, bounded rationality and social preferences. This paper has provided a number of illustrations of how to accomplish this. 
Up till now, evolutionary economics has hardly devoted attention to environmental and resource dimensions of economic systems. The neo-Schumpeterian school in evolutionary economics has been occupied with technological innovations that occur over relatively short time horizons - at least from an environmental-biological evolutionary angle. The other component of evolutionary economics, evolutionary game theory, has dealt with simple, analytical models that represent the essence of selection dynamics, thereby completely ignoring the long-term impact of innovation on the adaptive capacity of systems. ${ }^{2}$ In the evolutionary-economic study of history, the neglect of environmental and resource dynamics may lead to a seriously incomplete model of reality. The reason is that important phases of economic history have been subject to strong influences from environmental and resource factors. This in any case holds for such major transitions as the development of agriculture and human settlements, and the Industrial Revolution. Energy scarcity and climate change may also be important triggering factors in any future economic transitions.

Given the broad range of themes covered here, it is difficult to summarize all relevant insights in a simple manner. The following is an account of the most important results and suggestions for research.

The discussion of evolutionary analysis at the level of ecosystems and natural resources (Section 3) suggests that attention for biological evolution will increase the realism of resource use or ecosystem management analysis and thus improve the robustness of findings (both fundamental and policy-relevant). In particular, (optimal) resource exploitation should take selection pressure impacts into account, which can conceptually be regarded as (slow) dynamic externalities that are not always evident to resource users or policy makers. In addition, evolutionary mechanism can underpin the notion of 'resilience' by offering microlevel mechanisms for both modelling and testing, addressing the phenomenon in both natural and economic (institutional) systems. Next, an important finding of evolved norms and rules in common-pool resource situations is that externally imposed rules and monitoring can reduce and destabilize co-operation or even completely destroy it, notably when monitoring is impossible or ineffective. The mechanisms behind the evolution of these norms are still not completely understood, in particularly the role of space (the local nature of interaction), punishment, the size of groups, and the type of resource dynamics. From a policy perspective, it is further relevant how to stimulate norms through communication or improving mutual trust. Such issues might also turn out to be relevant for the formation and stability of international agreements, such as in

\footnotetext{
2 'Equilibrium selection theory' is therefore perhaps a more appropriate name. 'Evolutionary game theory' is better reserved for game approaches that combine selection and innovation to explain adaptation.
} 
relation to climate policy. Finally, the combined dynamics economic evolution and renewable resource dynamics is not well understood. Partly, this is due to the fact that a complete analytical resolution of this has proven to be very difficult if not impossible. Numerical approaches, on the other hand, do not render very general results, as they are restricted to certain parameter values (or at best ranges).

Economic growth with environment and resources was examined from an evolutionary angle in Section 4. It turns out that research using evolutionary elements here is very fragmented and ad hoc. It is thus hardly possible to draw conclusions about firm insights. Most importantly, evolutionary growth theory may be extended with environmental and resource variables to examine the interrelation of innovation policy, environmental regulation, selection environment, resource scarcity, and economic growth and development. It was argued that major transitions in human-economic history can only be fully understood if the coevolutionary role of environmental resources is sufficiently recognized. Although the term coevolution is regularly used, it often just denotes co-dynamics. Coevolution in a strict sense here denotes dynamic heterogeneous populations of strategies, organizations, institutions and technologies that influence each other's selection environment. Modelling coevolution can benefit from work in biology and anthropology that has provided an interesting typology of coevolution. Inspiration can further be drawn from approaches adopted by such different authors as Faber and Proops, Galor and Moav, and Epstein and Axtell.

The notion of progress in an evolutionary context was the subject of Section 5. Evolutionary theory and psychology have been invoked to support criticism on GDP growth as a social objective. The distinction between basic and higher needs (lexicographic preferences) is relevant here. Once basic needs are satisfied, one is in the realm of the higher needs. Here the notion of relative or context-dependent well-being is relevant, which expresses itself through comparison and rivalry with others. These explain the striving for conspicuous consumption and status goods. Evolutionary biology shows that the function of conspicuous and extravagant traits has a function, namely to improve the chance of finding a sexual partners and having offspring. Sexual selection has fixed this behavior in our genes. Rivalry has been negatively characterized as a "rat race", resembling the "Red Queen hypothesis", which emphasizes repeated selection for fitness so as not to be taken over by others. Progress of an economy seen as an evolutionary system was shown to have a number of possible dimensions: increasing diversity, increasing complexity, extended labor division, new ways of transmitting information, population growth, being adapted to the environment, and increasing efficiency of energy capture and transformation. The correlation between these is often high, though not always. Progress is a characterization that 
many evolutionary biologists try to avoid when discussing biological evolutionary processes, as there are several reasons why evolution does not necessarily give rise to progress: selection is a local search process, adaptations are often compromises between different objectives or selection pressures, (sub)systems are locked into historical constraints (lock-in), not all evolution is adaptive microevolution, and agents are boundedly rational. Moreover, virtually all evolution is coevolution, which means that the environment is not fixed, in turn making adaptations temporary effective and rapidly superseded. Environmental economic models should be consistent with these insights in the sense of formulating and using social objective functions incorporating evolutionary notions. In empirical research, the focus on GDP growth should be critically looked upon. Search for alternative progress indicators might take the potential for evolutionary progress into consideration, which would mean assigning a central role to the notion of diversity. This will then allow for thoroughly dealing with distribution, relative welfare, and rivalry issues in a system-wide context.

Additional policy issues were addressed in a separate section (Section 6). Some important insights here are as follows. Loss of diversity at any level hampers potential fitness improvements through selection as well as innovation opportunities through recombination. Preventing (early) lock-in requires a kind of portfolio investment. Here, the short-term costs and long-term benefits of diversity need to be balanced. Evolutionary models are especially helpful in assessing the longterm benefits of diversity. Further, un-locking of (sub)systems requires more than 'correcting prices' for environmental externalities, notably taking account of increasing returns on both demand and supply sides of markets. Policy of this type resembles advice by resilience and adaptive management 'schools', which focus on diversity and learning. In any case, without waste, one can be sure that one has been too careful as evolution is characterized by many failures for each success: without wasteful diversity and experiments, there can indeed be no evolutionary progress. Last but not least, incentives should go beyond narrow economic, monetary interests and take social interactions and reputation effects into account. Application of group selection theory may be useful here, as group phenomena can be linked to a variety of social (or non-selfish or other-regarding) preferences, such as reciprocal fairness, inequity aversion, pure altruism, altruistic punishment and spite or envy. This is relevant to both resource use and environmental externality contexts. Fairness sentiments can explain, for example, why environmental conflicts are more common than (Coase type) negotiations.

It is good to stress that evolution was used here to cover sometimes biological and in other cases economic phenomena. Certain applications in resource economics and environmental growth theory can benefit from the inclusion of biological (genetic) evolutionary mechanisms. On 
the other hand, economic (non-genetic) evolutionary mechanisms, covering market, technological, institutional and organizational aspects, are relevant to virtually all themes within environmental economics.

Finally, it is fair to note that because of size limits the list of suggestions for research opportunities on the boundary of evolutionary and environmental economics is necessarily incomplete. One main area of research that deserves at least mention is 'environmental aesthetics', the idea that people derive happiness from nature. Environmental economists have tried to capture this with the help of monetary valuation studies. Penn (2003) refers in this context to E.O. Wilson's (1984) notion of 'biophilia', which conveys the message that humans have instinctive, genetically based, preferences for natural environments and other species with certain features. In particular, we seem to like savannah type of landscapes, as these represent the habitat to which we adapted through biological evolution. Possibly, such evolutionary insights can aid in devising strategies to increase democratic support for environmental protection.

With regard to the future, one worrying scenario that comes to mind is the collapse of modern economies due to severe climate change. But as one respected thinker has noted: "Perhaps, the destiny of man is to have a short, but fiery, exciting and extravagant life rather than a long, uneventful and vegetative existence.” (Georgescu-Roegen, 1972, p. 35). The nature of evolution, survival so as to reproduce rather than to grow old (Hamilton, 1966), suggests that this is not unlikely. Admittedly, the analogy between individuals and species adopted here may be farfetched. In other words, one should not feel guilty about being optimistic.

\section{References}

Allen, C.R. (2001). Ecosystems and immune systems: hierarchical response provides resilience against invasions. Conservation Ecology 5(1): 15. [online] URL: http://www.consecol.org/vol5/iss1/art15/

Andreoni, J. (1990). Impure altruism and donations to public goods: A theory of warm-glow giving. Economic Journal 100: 464-477.

Arthur, B. (1989). Competing technologies, increasing returns, and lock-in by historical events. Economic Journal 99: 116-131.

Axelrod, R. (1986). An evolutionary approach to norms. American Political Science Review 80(4): 222-238.

Ayres, R.U. (1994). Information, Entropy and Progress: Economics and Evolutionary Change. AEP Press, Washington. 
Azar, C. (1998). Are optimal CO2 emissions really optimal? Environmental and Resource Economics 11: 301-315.

Baumgärtner, S. (2004). Optimal investment in multi-species protection: interacting species and ecosystem health. Ecohealth 1: 101-110.

Baumol, W.J. and W.E. Oates (1988). The Theory of Environmental Policy. 2nd ed. Cambridge University Press, Cambridge, UK.

Bergstrom, T.C. (2002). Evolution of social behavior: individual and group selection. Journal of Economic Perspectives 16(2): 67-88.

Bianciardi, C., E. Tiezzi and S. Ulgiati (1993). Complete recycling of matter in the frameworks of physics, biology and ecological economics. Ecological Economics 8: 1-5.

Boulding, K.E. (1978). Ecodynamics: A New Theory of Societal Evolution. Sage Publications, Beverly Hills.

Boulding, K.E. (1981). Evolutionary Economics. Sage Publications, Beverly Hills.

Brekke, K.A., and R.B. Howarth (2002). Status, Growth, and the Environment: Goods as Symbols in Applied Welfare Economics. Edward Elgar, Cheltenham.

Brock, W.A., and A. Xepapadeas (2003). Valuing Biodiversity from an Economic Perspective: A Unified Economic, Ecological, and Genetic Approach. American Economic Review 93(5): 1597-1614.

Bromley, D.W. (ed.) (1992). Making the Commons Work: Theory, Practice, and Policy. ICS Press, San Francisco.

Buenstorf, G. (2000). Self-organization and sustainability: energetics of evolution and implications for ecological economics. Ecological Economics 33: 119-134.

Buss, D.M. (1989). Sex differences in human mate preferences: evolutionary hypotheses tested in 37 cultures. Behavioral and Brain Sciences 12: 1-49.

Campbell, N.A. (1996). Biology. $4^{\text {th }}$ edition. The Benjamin/Cummings Publishing Company, Menlo Park, Ca.

Clark, C.W. (1990). Mathematical Bioeconomics: The Optimal Management of Renewable Resources. 2nd ed. Wiley, New York.

Coase, R. (1960). The problem of social cost. Journal of Law and Economics 3: 1-44.

Common, M. (1988). Poverty and progress revisited. In: D. Collard, D.W. Pearce and D. Ulph (eds.). Economics, Growth and Sustainable Environments. St. Martin's Press, New York, pp. 15-39. 
Common, M., and U. Neuman (2005). Agent based simulation modeling for sustainability analysis: introducing irreversibility and precautionary behaviour to the Sugarscape. http://homepages.strath.ac.uk/ cds98101/agent1.html.

Common, M., and C. Perrings, 1992. Towards an ecological economics of sustainability. Ecological Economics 6: 7-34.

Conlisk, J. (1989). An aggregate model of technical change. Quarterly Journal of Economics 104: 787-821.

Conway Morris, C. (2003). Life's Solution: Inevitable Humans in a Lonely Universe. Cambridge University Press, Cambridge, UK.

Costanza, R. (ed.) (1991). Ecological Economics: The Science and Management of Sustainability, Columbia University Press, New York.

Costanza, R., L. Wainger, C. Folke, and K.-G. Maler (1993). Modeling complex ecological economic systems: towards an evolutionary, dynamic understanding of people and nature. BioScience 43: 545-555.

Couclelis, H. (1985). Cellular worlds: a framework for modeling micro-macro dynamics. Environment and Planning A 17, pp. 585-596.

Daly, H.E., and J. Cobb (1989). For the Common Good: Redirecting the Economy Toward Community, the Environment, and a Sustainable Future. Beacon Press, Boston, MA.

Dasgupta, P.S. and G.M. Heal (1979). Economic Theory and Exhaustible Resources, Cambridge University Press, Cambridge, UK.

Dawkins, R. (1982). The Extended Phenotype. Oxford University Press, Oxford.

Dawkins, R. (1997). Human chauvinism and evolutionary progress. Evolution 51(3): 1015-20.

Diamond, J. (1997). Guns, Germs and Steel: The Fates of Human Societies, W. W. Norton, New York.

Dixit, A.K., and R.S. Pindyck (1994). Investment under Uncertainty. Princeton University Press, Princeton, N.J.

Durham, W.H. (1991). Coevolution: Genes, Culture and Human Diversity. Stanford University Press, Stanford.

Ecological Economics 22(3) (1997). Special issue: 'The contribution of Nicholas GeorgescuRoegen'.

Elzen, B., F. Geels and K. Green (2004) (eds.). System Innovation and the Transition to Sustainability: Theory, Evidence and Policy. Edgar Elgar, Cheltenham.

Epstein, C., and R. Axtell (1996). Growing Artificial Societies: Social Science from the Bottom Up. The MIT Press, Boston, Mass. 
Faber, M. and J.L.R. Proops (1990). Evolution, Time, Production and the Environment. SpringerVerlag, Heidelberg.

Fehr, E., and U. Fischbacher (2002). Why social preferences matter - the impact of non-selfish motives on competition, cooperation and incentives. Economic Journal 112: C1-C33.

Fisher, A.C. (2000): Investment under uncertainty and option value in environmental economics. Resource and Energy Economics 22(3): 197-204.

Freeman III, A.M. (1993). The Measurement of Environmental and Resource Values: Theory and Methods. Resources for the Future, Baltimore.Fisher, A.C. (2000). Investment under uncertainty and option value in environmental economics. Resource and Energy Economics 22(3): 197-204.

Galor, O., and O. Moav (2002). Natural selection and the origin of economic growth. Quarterly Journal of Economics 117(4): 1133-1191.

Georgescu-Roegen, N. (1971). The Entropy Law and the Economic Process. Harvard University Press, Cambridge, MA.

Georgescu-Roegen, N. (1972). Energy and economic myths. in: N. Georgescu-Roegen (ed., 1976). Energy and Economic Myths. Pergamon, New York.

Gould, S.J. (1988). On Replacing the Idea of Progress with an Operational Notion of Directionality. In: M. Nitecki (ed.). Evolutionary Progress. University of Chicago Press, Chicago.

Gould, S.J., and R.C. Lewontin (1979). The spandrels of San Marco and the Panglossian paradigm: A critique of the adaptationist programme. Proceedings of the Royal Society of London B 205: 581-98.

Gowdy, J. (1994). Coevolutionary Economics: The Economy, Society and the Environment. Kluwer Academic Publishers, Dordrecht.

Gowdy, J. (1999). Evolution, environment and economics. In: J.C.J.M. van den Bergh (ed.). Handbook of Environmental and Resource Economics. Edward Elgar, Cheltenham.

Grimm, V. (1999). Ten years of individual-based modeling in ecology: what have we learned and what could we learn in the future. Ecological Modelling 115(2-3): 129-148.

Gunderson, L., and C.S. Holling (2002). Panarchy: Understanding Transformation in Human and Natural Systems. Island Press, Washington D.C.

Hamilton, W.D. (1966). The moulding of senescence by natural selection. Journal of Theoretical Biology 12(1): 12-45.

Hannan, M.T., and J. Freeman (1989). Organizational Ecology. Harvard University Press, Cambridge, MA. 
Hanley, N. and C.L. Spash (1993). Cost-Benefit Analysis and the Environment. Edward Elgar Publishers, Aldershot.

Hardin, G. (1968). The tragedy of the commons. Science 162: 1243-1248.

Hausfather, Z. (2006). Implications of strong reciprocal behavior on coasian bargains. Module 4 Paper, Masters programme “Environmental and Resource Management”, Institute for Environmental Studies, Free University, Amsterdam.

Heide, C.M. van der, J.C.J.M. van den Bergh and E.C. van Ierland (2005). Extending Weitzman's economic ranking of biodiversity protection: combining ecological and genetic considerations. Ecological Economics 55: 218-223.

Henrich, J. (2004). Cultural group selection, coevolutionary processes and large-scale cooperation. Journal of Economic Behavior and Organization 53: 3-35.

Hirsch, F. (1976). Social Limits to Growth. Harvard University Press, Cambridge, Mass.

Hoekstra, R., and J.C.J.M. van den Bergh (2005). Harvesting and conservation in a predator-prey system. Journal of Economic Dynamics and Control 29(6): 1097-1120.

Holling, C.S. (1973). Resilience and stability of ecological systems. Annual Review of Ecological Systems 4: 1-24.

Holling, C.S. (1986). The resilience of terrestrial ecosystems: Local surprise and global change. In: W. C. Clark and R. E. Munn (ed.). Sustainable Development of the Biosphere. Cambridge University Press, Cambridge, UK.

Holling, C.S., D.W. Schindler, B. Walker and J. Roughgarden (1994). Biodiversity in the functioning of ecosystems: an ecological primer and synthesis. In: C. Perrings, K.-G. Mäler, C. Folke, C.S. Holling and B.-O. Jansson (eds.). Biodiversity Loss: Ecological and Economic Issues. Cambridge University Press, Cambridge, UK.

Horan, R.D., E. Bulte and J. F. Shogren (2005). How trade saved humanity from biological exclusion: an economic theory of Neanderthal extinction. Journal of Economic Behaviour and Organization 58(1): 1-29.

Howarth, R.B., en K.A. Brekke (2003). Status, Growth and the Environment: Goods As Symbols in Applied Welfare Economics Edward Elgar Publishing, Cheltenham.

Iwai, K. (1984). Schumpeterian dynamics, part I: an evolutionary model of innovation and imitation. Journal of Economic Behaviour and Organization 5(2): 159-190.

Jaffe, A.B., R.G. Newell and R.N. Stavins (2001). Environmental Policy and Technological Change. Environmental and Resource Economics 22 (1-2): 41-69.

Janssen, M. A. 2001. An immune system perspective on ecosystem management. Conservation Ecology 5(1): 13 [online] URL: http://www.consecol.org/vol5/iss1/art13. 
Janssen, M. (ed.) (2002). Complexity and Ecosystem Management: The Theory and Practice of Multi-agent Systems. Edward Elgar, Cheltenham, UK.

Janssen, M., and E. Ostrom (2005). Governing social-ecological systems. In: K.L. Judd and L. Tesfatsion (eds.). Handbook of Computational Economics II: Agent-based Computational Economics. North-Holland, Amsterdam.

Janssen, M., and B. de Vries (1998). The battle of perspectives: a multi-agent model with adaptive responses to climate change. Ecological Economics 26: 43-66.

Johansson, P.-O. (1987). The Economic Theory and Measurement of Environmental Benefits. Cambridge University Press, Cambridge, UK.

Johansson, P.O., and K.G. Löfgren (1985). The Economics of Forestry and Natural Resources. Basil Blackwell, Oxford.

Kahneman, D., J. Knetsch, and R. Thaler (1990). Experimental tests of the endowment effect and the Coase theorem. Journal of Political Economy 98: 1325-1348.

Kauffman, S.A. (1993). The Origins of Order: Self-Organization and Selection in Evolution. Oxford University Press, Oxford.

Kemp, R. (1997). Environmental policy and Technical Change: A Comparison of the Technological Impact of Policy Instruments. Edward Elgar, Cheltenham.

Layard, R. (2005). Happiness: Lessons from A New Science. Penguin, London.

Levin et al. (17 authors) (1998). Resilience in natural and socioeconomic systems. Environment and Development Economics 3(2): 222-235.

Löschel, A. (2002). Technological change in economic models of. environmental policy: a survey. Ecological Economics 43: 105-126.

Mäler, K.-G., A. Xepapadeas, and A.J. de Zeeuw (2003). The economics of shallow lakes. Environmental and Resource Economics 26(4): 603-624.

Martin, F. (1989/1992). Common-pool resources and collective action: a bibliography. Vols. 1 and 2. Workshop in Political Theory and Policy Analysis. Indiana University, Bloomington.

Martinez-Alier, J. (2005). The Environmentalism of the Poor: A Study of Ecological Conflicts and Valuation. Oxford University Press, Oxford.

Maynard Smith, J., and E. Szathmáry (1995). The Major Transitions in Evolution. Oxford University Press, Oxford.

Mulder, P., and J.C.J.M. van den Bergh (2001). Evolutionary economic theories of sustainable development. Growth and Change 32(4): 110-134.

Munro, A. (1997). Economics and biological evolution. Environmental and Resource Economics 9: 429-449. 
Nelson, R., and S. Winter (1982). An Evolutionary Theory of Economic Change. Harvard University Press, Cambridge, MA.

Noailly, J. (2003). Coevolutionary Modelling for Sustainable Economic Development. PhD thesis, Free University, Tinbergen Institute and Thesis Publishers, Amsterdam.

Noailly, J., J.C.J.M. van den Bergh and C. Withagen (2003). Evolution of harvesting strategies: replicator and resource dynamics. Journal of Evolutionary Economics 13(2): 183-200.

Noailly, J., J.C.J.M. van den Bergh and C. Withagen (2006). Spatial evolution of social norms in a common pool resource game. Environmental and Resource Economics, forthcoming.

Nordhaus, W.D. (1994). Managing the Global Commons: The Economics of Climate Change, MIT Press, Cambridge, MA

Norgaard, R.B. (1984). Coevolutionary development potential. Land Economics 60: 160-173.

Norgaard, R.B. (1994). Development Betrayed: The End of Progress and a Coevolutionary Revisioning of the Future. Routledge, London and New York.

O'Connor, M. (1991). Entropy, structure, and organisational change. Ecological Economics 3(2): 95-122.

Ofek, H. (2001). Second Nature: Economic Origins of Human Evolution. Cambridge University Press, Cambridge, UK.

Ostrom, E. (1990). Governing the Commons: The Evolution of Institutions for Collective Action New York. Cambridge University Press, Cambridge.

Ostrom, E. (2000). Collective action and the evolution of social. Norms. Journal of Economic Perspectives 14(3): 137-158.

Penn, D.J. (2003). The evolutionary roots of our environmental problems: towards a Darwinian ecology. The Quarterly Review of Biology 78(3): 275-301.

Perrings, C., K-G. Maler, C. Folke, C.S. Holling and B-O. Jansson (eds.) (1995). Biodiversity Loss: Economic and Ecological Issues. Cambridge University Press, Cambridge.

Pimm, S.L. (1984). The complexity and stability of ecosystems. Nature 307: 321-326.

Pindyck, R.S. (2000). Irreversibilities and the timing of environmental policy. Resource and Energy Economics 22: 233-259.

Potts, J. (2000). The New Evolutionary Microeconomics: Complexity, Competence, and Adaptive Behavior. Edward Elgar, Cheltenham, UK.

Rammel, C., and J.C.J.M. van den Bergh (2003). Evolutionary policies for sustainable development: adaptive flexibility and risk minimising. Ecological Economics 47 (2): 121-133.

Roe, E.M. (1996). Sustainable development and Girardian economics. Ecological Economics 16: 87-93. 
Ruse, M. (1999). Mystery of Mysteries: Is Evolution a Social Construction. Harvard University Press, Cambridge, Mass.

Saint-Jean, M. (2006). Environmental innovation and policy: lessons from an evolutionary model of industrial dynamics. Essay for a workshop on "Evolutionary modelling and environmental policy”, organised by the Netherlands Environmental Assessment Agency, Amsterdam, May $18^{\text {th }}, 2006$.

Schneider, E.D., and J.J. Kay (1994). Life as a manifestation of the second law of thermodynamics. Mathematical and Computer Modelling 19(6-8): 25-48.

Schwoon, M. (2006). Simulating the adoption of fuel vehicles. Journal of Evolutionary Economics 16: 435-472.

Sen, A. (1993). On the Darwinian view of progress. Population and Development Review 19(1): 123-137.

Sethi, R., and E. Somanathan (1996). The evolution of social norms in common property resource use. American Economic Review 86(4): 766-788.

Silverberg, G., G. Dosi, and L. Orsenigo. (1988). Innovation, diversity and diffusion: a self-organization model. Economic Journal 98: 1032-1054.

Strickberger, M.W. (1996). Evolution. $2^{\text {nd }}$ ed. Jones and Bartlett Publishers, Sudbury, Mass. Swanson, T.M. (1994). The Economics of Extinction Revisited and Revised: A Generalised Framework for the Analysis of the Problems of Endangered Species and Biodiversity Losses. Oxford Economic Papers 46: 800-821.

Toman, M.A., J. Pezzey and J. Krautkraemer (1995). Neoclassical economic growth theory and ‘sustainability’. In: D.W. Bromley (ed.), Handbook of Environmental Economics. Blackwell, Oxford.

Tversky, A., en I. Simonson (2000). Context-dependent preferences. In: D. Kahneman en A. Tversky (eds.), Choices, Values and Frames. Cambridge University Press, Cambridge, pp. 518-527.

Unruh, G.C. (2002). Escaping carbon lock-in. Energy Policy 30: 317-325.

van den Bergh, J.C.J.M. (2001). Ecological economics: themes, approaches, and differences with environmental economics. Regional Environmental Change 3(1): 13-23.

van den Bergh, J.C.J.M. (2004). Optimal climate policy is a utopia: from quantitative to qualitative cost-benefit analysis. Ecological Economics 48: 385-393.

van den Bergh, J.C.J.M. (2005). An evolutionary analysis of growth, environment and resources. In: R.U. Ayres, D. Simpson and M. Toman. Scarcity and Growth in the New Millennium. Resources for the Future, Washington D.C. 
van den Bergh, J.C.J.M. (2006). Abolishing GDP: The Largest Information Failure in the World.

Working paper, Dept. of Spatial Economics, Free University, Amsterdam.

van den Bergh, J.C.J.M., A. Ferrer-i-Carbonell en G. Munda (2000). Alternative models of individual behaviour and implications for environmental policy. Ecological Economics 32(1): 43-61.

van den Bergh, J.C.J.M., and J.M. Gowdy (2002). The microfoundations of macroeconomics: an evolutionary perspective. Cambridge Journal of Economics 27(1): 65-84.

van den Bergh, J.C.J.M., and R.A. de Mooij (1999). An assessment of the growth debate. In:

J.C.J.M. van den Bergh (ed.) Handbook of Environmental and Resource Economics. Edward Elgar, Cheltenham.

van den Bergh, J.C.J.M., and S. Stagl (2003). Coevolution of economic behaviour and institutions: towards a theory of institutional change. Journal of Evolutionary Economics 13 (3): 289-317.

van den Bergh, J.C.J.M., A. Faber, A.M. Idenburg and F.H. Oosterhuis (2006). Survival of the greenest: Evolutionary economics and policies for energy innovation. Environmental Sciences 3(1): 57-71.

van den Bergh, J.C.J.M., A. Faber, A.M. Idenburg and F.H. Oosterhuis (2007). Evolutionary

Economics and Environmental Policy: Survival of the Greenest. Edward Elgar Publ., Cheltenham, forthcoming.

van den Heuvel, S.T.A., and J.C.J.M. van den Bergh (2005). Balancing diversity and efficiency: multilevel evolutionary dynamics in the solar photovoltaic industry. Working paper, Department Of Spatial Economics, Free University, Amsterdam.

van der Voet, E., R. Huele en R. Stevers (2000). Evolutionary Predators, prey, pets and pests: evolutionary reactions on human dominance in the biosphere. Unpublished.

Veblen, T. (1899). The Theory of the Leisure Class. Penguin Books, New York.

Walker, B., S. Carpenter, J. Anderies, N. Abel, G. S. Cumming, M. Janssen, L. Lebel, J. Norberg, G. D. Peterson, and R. Pritchard (2002). Resilience management in social-ecological systems: a working hypothesis for a participatory approach. Conservation Ecology 6(1): 14. [online]

URL: http://www.consecol.org/vol6/iss1/art14/

Walters, C. (1986). Adaptive Management of Renewable Resources. MacMillan, New York.

Weitzman, M.L. (1993). What to preserve? An application of diversity theory to crane conservation. Quarterly Journal of Economics 108 (1): 157-183.

Weitzman, M.L. (1998). The Noah’s ark problem. Econometrica 66: 1279-1298. 
Wilkinson, R. (1973). Poverty and Progress: An Ecological Model of Economic Development, Methuen and Co., London.

Wilson, E.O. (1975). Sociobiology: The New Synthesis. Harvard University Press, Cambridge, Mass.

Wilson, E.O. (1984). Biophilia: The Human Bond with Other Species. Harvard University Press, Cambridge, Mass.

Winder, N., B.S. McIntosh and P. Jeffrey (2005). The origin, diagnostic attributes and practical application of co-evolutionary theory. Ecological Economics 54(4): 347-361. 